\title{
DIFICULDADES NA IMPLANTAÇÃO DA EQUIPE DE TÉCNICOS EM BANCO DE OLHOS EM HOSPITAL UNIVERSITÁRIO
}

\author{
Difficulties in implanting a team of technicians in an eye bank at an university hospital
}

Débora Cristina Gabriel, Elcio Hideo Sato

\begin{abstract}
RESUMO
Objetivo: Determinar as principais dificuldades e impactos vividos pelos Técnicos em Banco de Olhos do Hospital São Paulo no início de sua atuação e identificar suas necessidades quanto à preparação e treinamento visando à melhora na qualidade. Métodos: Foi aplicado um questionário sobre as dificuldades e os impactos vividos pelos Técnicos em Banco de Olhos do Hospital São Paulo, Hospital Universitário aos quatro profissionais da equipe. Resultados: A análise qualitativa das respostas mostrou que as dificuldades referem-se à falta de experiência na técnica de captação dos olhos doados; à falta de segurança no percurso ao necrotério à noite e à limitação de transporte para a captação em outros hospitais. Segundo o questionário, o maior impacto vivido foi a entrevista das famílias dos possíveis doadores. Conclusão: Há necessidade de preparação e treinamento específicos para a atuação do Técnico em Banco de Olhos, que requer prática e habilidade, que serão adquiridas com a aplicação da técnica em diversas doações. Grande importância deve ser dada na preparação específica da entrevista familiar, para que a doação dos olhos não seja transformada em experiência negativa.
\end{abstract}

Descritores: Bancos de olhos, córnea, morte

Instituiç̧ão:

Banco de Olhos do Hospital São Paulo - UNIFESP

Correspondência:

Elcio H. Sato

Av. Paulista, 726 - 301 - São Paulo / SP - CEP: 01310-910 - Brasil

Fax: (11) 32885987

E-mail: esato@oftalmo.epm.br

Recebido em: 16.06 .2008

\section{INTRODUÇÃO}

Os avanços constantes nas técnicas relacionadas aos Bancos de Olhos, como processamento dos tecidos e avaliação e preservação das córneas tem propiciado um aumento no número de transplantes que, no entanto, está abaixo do necessário no Brasil. Portanto, nos deparamos com a necessidade de crescimento e profissionalização para atender a demanda. ${ }^{1-3}$

Atualmente, o Banco de Olhos tem as seguintes atribuições: entrevistar a família do possível doador, captar a córnea doada; selecionar tecido com boa transparência e vitalidade; preservar a córnea; estocar e liberar o tecido para transplante. Uma de suas atribuições é realizar a triagem clínica e laboratorial, de forma a evitar a possibilidade de transmissão de doenças ao receptor pelo transplante. $^{2}$

Para o Banco de Olhos desempenhar bem essas atividades, ele deve se ocupar de todo processo de doação, que se inicia externamente, com a entrevista familiar, triagem clínica e laboratorial do doador, passando pela criteriosa avaliação e processamento do tecido doado e finalmente liberação do tecido de excelente qualidade para transplante..$^{2,4}$

A portaria 3407/GM de 5 de agosto de 1998 do Ministério da Saúde permite a atividade do técnico em Banco de Olhos (TBO), sob responsabilidade de um médico oftalmologista autorizado. Portanto, a equipe integrada pelo TBO precisa estar apta aos procedimentos técnicos cirúrgicos da doação e para interagir com os familiares dos possíveis doadores. Essa interação é de igual importância às habilidades técnicas, pois o papel social do Banco de Olhos não é 
causar uma experiência negativa para as famílias dos doadores, já desgastada com a perda de um familiar, mas o de fazer da doação um ato fortalecedor e benéfico diante do acontecimento, ajudando, assim, a desmistificar o ato da doação de órgãos e tecidos e estimular futuras doações. ${ }^{2}$

Os TBO têm a função de entrevistar as famílias na busca de doadores, realizarem a triagem clínica dos doadores, retirarem amostra sanguínea para realização de exames sorológicos, realizarem a enucleação, preservarem os tecidos e avaliarem as córneas doadas.

A equipe do Banco de Olhos deve ser bem preparada e treinada nos diversos aspectos que envolvem sua rotina. O preparo está diretamente ligado a efetivar as doações, pois, saber lidar com as famílias na elaboração do luto pode ajudá-los a optar pela decisão de doar e assim otimizar a eficiência do Banco de Olhos.

Para o treinamento e preparo adequados almeja-se atingir as mais diversas necessidades e possíveis vivências da equipe; não deixando questões ligadas a cada Instituição e respeitando as diferenças culturais e sociais da região em que se insere o Banco de Olhos.

\section{OBJETIVO}

Determinar as principais dificuldades e maiores impactos vividos pelos TBO do Hospital São Paulo na fase inicial de sua atuação e identificar suas necessidades quanto à preparação e treinamento, visando a melhora da qualidade do Banco de Olhos.

\section{MÉTODOS}

Elaboração de questionário sobre as dificuldades e os impactos vividos nas três primeiras semanas como TBO do Hospital São Paulo - um Hospital Universitário com atendimento em sua maioria pelo SUS (Sistema Único de Saúde), situado em São Paulo, Brasil, aplicando-o a quatro profissionais da equipe.

Esse questionário continha as seguintes perguntas objetivas e permitia respostas dissertativas, para que houvesse exposição das idéias dos que o responderam:

1. Quais dificuldades você encontrou nas três primeiras semanas como Técnico em Banco de Olhos?

2. Qual o maior impacto vivido no mesmo período?

3. Você notou em você alguma alteração comportamental nessa mesma época?

\section{RESULTADOS}

A análise qualitativa das respostas mostrou que as dificuldades encontradas referem-se à falta de experiência na técnica de captação dos olhos doados, principalmente na retirada de sangue para realização dos exames sorológicos e com as esporádicas hemorragias secundárias à enucleação; falta de segurança existente no percurso entre a sede do Banco de Olhos e o necrotério do Hospital, que foi realizado pelo lado externo em ruas escuras no período noturno e limitação de transporte próprio do Hospital para captação em outros hospitais.

Segundo o questionário, o maior impacto vivido foi na entrevista com as famílias dos possíveis doadores; lidar com as mais diversas reações apresentadas pelos familiares no processo de perda e luto, nos diversos tipos de óbito, provocando uma intensa carga emocional.
Entrar em contato com a morte de forma corriqueira e direta levou a uma exacerbação das defesas psíquicas, desencadeando diversos fenômenos, como a projeção da própria limitação existencial. Para os plantonistas, a espera que uma doação acontecesse provocou sensações conflituosas de desejar a ocorrência de um óbito.

\section{DISCUSSÃO}

As dificuldades de caráter institucional encontradas podem ser superadas com atuação conjunta da equipe do Banco de Olhos e a administração do Hospital. Tais dificuldades evidenciam que as Instituições, em geral, não estão direcionadas à prática da doação de córneas e cabe à equipe dinamizar a rotina, inserindo esse hábito dentro da Instituição. Com base nas questões de segurança no trajeto do $\mathrm{BO}$ até o necrotério à noite, foi solicitado o acompanhamento de uma pessoa da segurança da Instituição.

Outras dificuldades ligadas aos procedimentos da captação de olhos referem-se à aquisição de habilidades e à prática, que são adquiridas com treinamentos específicos e a repetição de tais condutas em diversas doações. Para a coleta de amostras sanguíneas para os exames sorológicos, devemos atentar para o conhecimento de anatomia, dos principais locais de acesso (subclávia, femural, intracardíaca) e as condições do corpo do doador, facilitando a escolha da via utilizada para a retirada. As hemorragias que podem ocorrer logo após a enucleação podem ser estancadas utilizandose diversas técnicas e manobras apropriadas, como a sutura em bloco. O conhecimento e o aprimoramento dessas técnicas são importantes para a equipe lidar com intercorrências e resolver as dificuldades de forma correta, sem prejudicar o tecido doado ou a aparência do doador. A realização incorreta dos procedimentos leva a prejuízos e danos para o olho captado e para a reconstituição da fisionomia do doador que passará pelo rito do funeral. Sabemos que a experiência, aqui, é facilitadora e apuradora da qualidade de todas as técnicas aplicadas. ${ }^{2}$

Para minimizar a dificuldade de transporte do TBO, ocorrência freqüente em Hospital Público, foi solicitado convênio com uma empresa de transporte. A agilidade da equipe do BO na captação é de fundamental importância na doação, podendo levar a família a desistir da doação, devido à demora da chegada da equipe, como também à perda da doação por ultrapassar o período máximo legal de seis horas para captação das córneas.

Dos impactos referidos, o maior foi lidar com a morte no cotidiano de trabalho, desencadeando algumas reações: experiências vivenciadas com o fenômeno da morte diante do falecimento de outrem, e pela definição atual de morte como cessação da função cerebral, que implica no fim da própria existência e separação dos entes queridos, defrontando-se com a definição de finitude. Assim, foi vivenciado o processo de projeção, onde há confrontação com as próprias limitações e medos, levando a uma exposição acentuada das defesas psíquicas, causando, na maioria das vezes, novas reflexões sobre conceitos e valores principalmente existenciais. ${ }^{5-7}$

Para os TBO, faz-se necessário conhecer os processos que envolvem o assunto, para diminuir os próprios conflitos desencadeados e lidar socialmente com os familiares dos possíveis doadores que estão em processo de elaboração da perda e do luto.

O luto é uma resposta humana normal da família e amigos após a morte de um ente querido. É comum que familiares utilizem mecanismos de defesa como negação, dissociação e projeção. 
Figura 1. Graduação progressiva das etapas do processo da elaboração do Luto vivenciado pelas famílias.

\author{
1. Choque e surpresa \\ 2. Alívio emocional \\ 3. Solidão \\ 4. Desconforto físico e ansiedade \\ 5. Pânico \\ 6. Culpa \\ 7. Hostilidade- projetada \\ 8. Desinteresse \\ 9. Vitória gradual sobre a tristeza \\ 10. Reajustamento à realidade
}

Projetam sobre a equipe ou o hospital a responsabilidade da morte. A ajuda mais significante nesse momento é a tolerância - se tolerarmos a raiva quer seja dirigida a nós, a Instituição, ao falecido, a Deus, teremos ajudado na aceitação sem culpa. Os diversos tipos de reações dos familiares podem estar classificados como: reação histérica, suicídio, abuso de fármacos psicoativos e abuso de álcool. ${ }^{8-10}$

Diversas teorias foram desenvolvidas para explicar o processo de elaboração desse luto. Cruz e cols. descrevem as etapas da elaboração do luto classificando-as em dez fases descritas na tabela. (Figura 1) ${ }^{10}$

Lidar com a preocupação da imagem do familiar é fator importante no caso da doação e é mais explícito em casos de mutilações nos últimos meses de vida. Estar preparado para solucionar possíveis problemas com as reações da família do doador deve fazer parte do preparo do TBO na entrevista familiar. ${ }^{10}$

O tipo de morte vivenciada pela família interfere na intensidade das reações ou cria um processo em que a culpa é substituída, mesmo que temporariamente, por revolta, ódio e raiva, como nos casos de morte traumática, violenta, inesperada, por tragédias e acidentes. A idade do ente falecido e a posição que ocupa na família são fatores que também agem sobre a intensidade das reações.7, 11,12
O complexo processo de perda envolve aceitações distintas: a cognitiva, a emocional e a adaptação ao novo mundo exterior e à nova realidade, que podem levar a um desvio do processo normal de luto, no qual o indivíduo se torna abatido e oprimido e lança mão de meios de enfrentamento mal-adaptativos que interferem com a habilidade individual de funcionamento das esferas cognitiva, comportamental e de desenvolvimento, chamado de luto patológico. Alguns sintomas e comportamentos sinalizam esse tipo de luto: aquisição de vários sintomas da doença do falecido; preocupação com pensamentos sobre o mesmo; descrença e falta de aceitação em relação à perda; hostilidade significativa em relação a pessoas ligadas à morte; atos prejudiciais à existência social e econômica do falecido; depressão agitada, incluindo sintomas de inutilidade; autoacusações amargas e necessidades óbvias de punição; falsa euforia subsequente à morte; impulsos auto-destrutivos e identificação excessiva com o falecido.,13

O conhecimento dos tipos de luto e em particular do luto patológico auxilia na prática da entrevista pelo TBO, pois as relações interpessoais podem estar comprometidas, sendo necessário o uso de técnicas para uma interação na comunicação nesses casos.

\section{CONCLUSÃO}

Há necessidade de preparação e treinamento específico para atuação dos Técnicos em Banco de Olhos, principalmente quando uma nova equipe é formada para dinamizar as doações dentro de um hospital ou instituição.

O treinamento técnico dos procedimentos realizados na doação dos olhos requer prática e habilidade que serão adquiridas com a aplicação da técnica em diversas doações e orientação do oftalmologista Diretor Médico do BO.

É dada uma grande importância na preparação específica da equipe com conhecimentos técnicos sobre o processo da morte e na elaboração do luto de um parente, para que a aceitação da doação dos olhos não seja transformada em um transtorno ou mais uma perda, e sim, numa experiência benéfica, assim como habilitar a equipe a lidar com as próprias emoções projetadas nesse momento.

\section{ABSTRACT}

Purpose: To determine main difficulties and impacts experienced by technicians from the São Paulo Hospital's Eye Bank in the beginning of their work, and to identify their needs concerning preparation and training, aiming to improve the quality. Methods: It was applied a questionnaire on the difficulties and impacts experienced by technicians from the Hospital São Paulo's Eye Bank, University Hospital to four professionals of that team. Results: Qualitative analysis of answers showed that difficulties were: lack of experience in the recovering the donated tissue technique; unsafe night conditions along the way to the morgue, the hospital's transportation scarcity to collect external donations. According to the questionnaire, the major impact was interviewing possible donors' families. Conclusion: It is necessary to prepare and perform specific training to technicians of the Eye Bank for a duty that requires practice and ability, which will be acquired upon applying the right technique in several donations. Great importance should be given to such specific preparation to perform the family interview in order to avoid the eye donation becomes a negative experience.

Keywords: Eye Banks, cornea, death 


\section{REFERÊNCIAS}

1. Rodrigues AM, Sato EH. Conhecimento e atitude da população do Hospital São Paulo sobre doação de córneas. Arq Bras Oftalmol. 2002;65,637-40.

2. Moreira H, Sousa L.B, Sato EH. Banco de olhos, transplante de córnea. Rio de Janeiro : Cultura Médica, 2008, v.1. p.214.

3. Sato, EH. Transplante de córnea e bancos de olhos no Brasil. J Bras Transpl. 2002;5:116-7.

4. Hirai FE, Adan CBD, Sato EH. Fatores associados à qualidade da córnea doada no Banco de Olhos do Hospital São Paulo. Arq Bras Oftalmol. 2009;75(1):57-61.

5. Kluber-Ross E. On Death and Dying. New York: Macmillan; 1977.p.174-8.

6. Boemer MR. A morte e o morrer. São Paulo: Cortez; 1986.p.49-60.

7. Neto AC, Majola RR. O luto normal, o luto patológico e o médico. Rev Med PUCRS 1997; 7(1):9-16
8. Guertzenstein EZ. Atendimento da relação de luto. Bol Centro Est Pesq Psiq 1987; $5: 33-5$.

9. Zavaschi MLS, Bassols AMS, Sanchez PC, Palma, RB. A reação da criança e do adolescente à doença e à morte: aspectos éticos. Bioética. 1993;1(2):165-72.

10. Simon R. Luto não elaborado e relação de tempo, lugar e memória. Bol Psicol. 1998; 48(108): 49-66.

11. Sousa LB, Chicani CF, Saud EE, Faria T, Sato EH. Perfil das doações de córnea no Banco de Olhos do Hospital São Paulo. Arq. Bras. Oftalmol.;1997;60:608-16.

12. Adan CB, Diniz AR, Perlatto D, Hirai FE, Sato EH. Dez anos de doação de córneas no Banco de Olhos do Hospital São Paulo: perfil dos doadores de 1996 a 2005. Arq Bras Oftalmol. 2008;71(2):176-81.

13. Cruz M, Rocha MCD, Silva MFP, Castelli M. Criança e doença fatal. Rio de Janeiro: Sarvier;1984.p. 81-100. 